\title{
Motivations and Effects Analysis of P3 Network Based on Cournot Model
}

\author{
L.J. Ma, L.J. Deng \\ Navigation College, Jimei University, Xiamen, Fujian, China
}

\begin{abstract}
After the formation of G6 Alliance, CKYH Alliance, Mediterranean Shipping and CMA-CGM Alliance, Maersk realized the importance of allying with other liner companies. Then, Maersk announced the alliance with Mediterranean Shipping and CMA-CGM in June last year, which meant the formation of P3 Long-term Network Alliance. The paper used Cournot Model to analyze the formation motivations of P3 Network as well as its possible effects.
\end{abstract}

KEYWORD: P3 Network; Cournot Model; Motivation Analysis; Effects

\section{INTRODUCTION}

Since twenty-first century, the shipping industry has been in a state of continuous adjustment, experiencing rounds and rounds of shipping alliances shuffling, the setup of the shipping world keeps changing. In the early, the New World Alliance, the Grand Alliance, the CKYH-Green and A.P. Muller-Maersk Group were in a situation of quadrupedal confrontations of the shipping world. In 2011, Maersk launched the "Daily Maersk" business model, the shipping world therefore came into a new shipping alliance reintegration stage. In December of 2011, MSC and CMA-CGM announced cooperation, being the Area Alliance to combat Maersk. At the end of the same year, the Grand Alliance and the New World Alliance announced cooperation, so G6 Alliance appeared. Others also began to take actions. In December 27 of 2011, EMC announced that it would cooperate with CKYH Alliance in AsianMediterranean routes and Europe-Asia routes, expanding the range and scope of service ports. Maersk came to realise the great importance of alliance,then in June of 2013, Maersk announced partnership with Aera Alliance, so, a long term operation alliance-P3 Network was in formating(Zhao,2014).

As the first tycoon of the liner shipping world, the big change of Maersk from fighting alone to joining alliance, meet the condition in the Cournot Model of Game Theory that two oligarchs change from independent decision-making to constructing alliance (Martin, 2005). In view of this, the paper uses Game Theory, by constructing the Cournot
Model to analyze the motivations and the possible effects of P3.

\section{COURNOT MODEL ESTABLISHMENT OF P3}

Cournot Model also names Cournot Duopoly Model, which was put forward by a French economistCournot in 1838. It is the first application of the Nash Equilibrium. Cournot Model assumes that there are only two competitors in the market, and the two have no collusion and they don't know opponent's action, they use there own way to determine the optimal production to realize their maximum profit respectively (Xie,2003). In order to facilitate the analysis of problems, the assumption here is both sides can accept the benefit allocation of the alliance.

Before the league, Maersk and Area Alliance were independent in the shipping market, providing the same liner service. And assuming that, on the same routes, the service price of Maersk is P1 and the service price of Area Alliance is $\mathrm{P} 2$, the freight volumes of them respectively are $\mathrm{q} 1$ and $\mathrm{q} 2$, the unit costs for providing service are $\mathrm{c} 1$ and c2 respectively. When the two sides compete each other in the market as the Cournot Model, the demand function of the both respectively are:

$P_{1}=P\left(q_{1}, q_{2}\right)$
$P_{2}=P\left(q_{1}, q_{2}\right)$

As profit $=$ revenue - cost, then can respectively obtain two parties' profits as: 


$$
\begin{aligned}
& \mathrm{U}_{1}=\mathrm{U}_{1}\left(\mathrm{q}_{1}, \mathrm{q}_{2}\right)=\mathrm{q}_{1} \mathrm{P}\left(\mathrm{q}_{1}, \mathrm{q}_{2}\right)-\mathrm{c}_{1} \mathrm{q}_{1} \\
& \mathrm{U}_{2}=\mathrm{U}_{2}\left(\mathrm{q}_{1}, \mathrm{q}_{2}\right)=\mathrm{q}_{2} \mathrm{P}\left(\mathrm{q}_{1}, \mathrm{q}_{2}\right)-\mathrm{c}_{2} \mathrm{q}_{2}
\end{aligned}
$$

In the Cournot competition, there exists a unique Nash Equilibrium Solution(Xie,2010). Their optimal capacities are affected by the rival's. The Nash Equilibrium Solution here is to find one enterprise's optimal production when the other one's optimal production is given(Maersk's optimal production is q1* and Area Alliance's is q2*)(Huo,2007). The necessary and sufficient condition for the existence of Nash Equilibrium Solution is the formula (2) taking the maximum value in the partial derivative at zero point, i.e.:

$$
\left\{\begin{array}{l}
\frac{\partial U_{1}}{\partial q_{1}}=P\left(q_{1}, q_{2}\right)+q_{1} \frac{\partial p\left(q_{1}, q_{2}\right)}{\partial q_{1}}-c_{1}=0 \\
\frac{\partial U_{2}}{\partial q_{2}}=P\left(q_{1}, q_{2}\right)+q_{2} \frac{\partial p\left(q_{1}, q_{2}\right)}{\partial q_{2}}-c_{2}=0
\end{array}\right.
$$

The market demand function $P=P\left(q_{1}, q_{2}\right)=a-q=a-\left(q_{1}+q_{2}\right), \quad a$ is a constant and $a>q_{1}+q_{2}$, used in the formula (3) can get:

$$
\left\{\begin{array} { l } 
{ a - 2 q _ { 1 } - q _ { 2 } - c _ { 1 } = 0 } \\
{ a - 2 q _ { 2 } - q _ { 1 } - c _ { 2 } = 0 }
\end{array} \Rightarrow \left\{\begin{array}{l}
q_{1}^{*}=\frac{a-2 c_{1}+c_{2}}{3} \\
q_{2}^{*}=\frac{a-2 c_{2}+c_{1}}{3}
\end{array}\right.\right.
$$

Use the above results in the formula (2) to get their profits respectively as:

$$
\begin{aligned}
& U_{1}=q_{1}\left(a-q_{1}-q_{2}\right)-c_{1} q_{1}=\left(\frac{a-2 c_{1}+c_{2}}{3}\right)^{2} \\
& U_{2}=q_{2}\left(a-q_{1}-q_{2}\right)-c_{2} q_{2}=\left(\frac{a-2 c_{2}+c_{1}}{3}\right)^{2}
\end{aligned}
$$

Their total profit is $U_{\text {Single }}=U_{1}+U_{2}$

After the formation of P3 Network, the two sides can obtain the scale effect. By the complementary advantages, resource integration, joint operations, joint decision-making they can reduce or even avoid unnecessary production links which can effectively reduce the unit cost of operation. Assuming that the total volume of P3 is q, the serving price is $p$, the unit cost of operation is $\mathrm{c}$, and its demand function is $\mathrm{P}(\mathrm{q})=\mathrm{a}-\mathrm{q}$. So its profit function:

$$
U(q)=q P(q)-c q=q(a-q)-c q
$$

The condition of P3 Network to have the optimal freight capacity is:

$$
\frac{\partial U}{\partial q}=a-2 q-c=0 \Rightarrow q^{*}=\frac{a-c}{2}(\text { optimalcapicity })
$$

Then the total profit of $\mathrm{P} 3$ is:
$U_{\text {Alliance }}=\mathrm{q}(a-q)-c q=\left(\frac{a-c}{2}\right)^{2}$

To simplify the analysis, it assumes the unit cost before the formation of $\mathrm{P} 3$ is $c_{1}=c_{2}=c_{0}$, then can get:

$U_{\text {Single }}=U_{1}+U_{2}=\frac{2\left(a-c_{0}\right)^{2}}{9}$

After the analysis, it can be drew that P3 can obtain the scale economies, reduce unnecessary production links, a 11 of which lead to the reduction of the unit operating cost, namely $c<c_{0}$, thereby, it significantly can compare:

$$
U_{\text {Alliance }}>U_{\text {Single }}, U_{\text {Alliance }}>U_{1} 、 U_{2}, \mathrm{q}^{*}>\mathrm{q} 1 * \mathrm{q} 2 *
$$

From the above analysis, shipping alliances not only can improve the service quality, reduce the unit cost of operation, but also can improve the total profit. Clearly, the efficiency and benefits of the alliance are both higher than that of shipping enterprises who make decisions alone. At the same time, as the shipping market is complex and changeable, joining in shipping alliances can be an effective way to deal with the challenge and to get rid of dilemma.

\section{MOTIVATIONS ANALYSIS OF P3 NETWORK FORMATION}

In the last four years, due to the impact of the world financial crisis, the container liner market had been in weakness, the vast majority of liner shipping business were in a state of loss. In face of shipping market downturn and low freight rate, many companies were in a loss, the whole shipping industry took counter measures. In order to improve performance, some enterprises chose to sell assets, such as: CMA CGM sold $49 \%$ shares of Terminal Link to the China Merchants Group in exchange for \$545000000(Liu,2014). Some declared bankruptcy, such as: in June of 2013, STX Pan Ocean formally submit the application to the America New York court for bankruptcy(Liu,2014). Some introduced partners to form alliance such as: G6 Alliance, CKYH Alliance, Area Alliance etc. Meanwhile, the first tycoon in the shipping industry, Maersk, was still fighting unsupported. Under this background, combined with the Cournot Model, the paper analyzes the main factors which lead to P3 formation as following:

First, the shipping market has been in downturn, competition between the liner companies is severe.Shipping alliance has become a major trend in development to draw on the advantages and avoid disadvantages, to reduce risk, obtain the competitive 
advantages, to defend their competitive positions in the market.

Second, to obtain scale benefit. Maersk will operate 20 super large vessels (180,000,000 TEU), which will bring a huge scale benefit. The Mediterranean and CMA CGM just see this advantage, hoping to obtain lower operating costs and achieve scale economies. Maersk also realizes that just having large shipping is not enough, obtaining sufficient goods is also necessary.

Third, to improve the quality of service. The three provide different service standards and have different clients, cooperation can expand their services scope. Through the operation of a unified management, they can allocate capacities more flexibly, can reduce the routes overlap rate, expand coverage, reduce the route unit operating costs, improve operational efficiency, and can provide more choices for customers, improve the quality of service. In addition, large-scale and energy-saving ships can reduce unit costs, reduce carbon emissions, protect environment.

The last, to shorten the gap and enhance their competitiveness. We all know the strength of CMA CGM are lower than that of Maersk and Mediterranean, and it was also in debt, so CMA CGM hopes to narrow the gap and get out of debt crisis as soon as possible. Allying with them is a good choice. For Mediterranean, hoping to improve its schedule stability, thereby to enhance reputation, shorten the gap between Maersk. Meanwhile, Maersk wants to take full advantage of super large vessels as well as to improve route density and port coverage, striving to hold the No.1..

Through alliance, they can make full use of cargo LCL, space exchange and information integration so as to achieve operational efficiency and get higher benefits. By sharing port resources and port docking can improve their direct service quantity and efficiency of port operations. Capacity integration and route adjustment, making them more vulnerable to the sudden change market demand, the flexibility of service is better. In short, all of them know what long-term benefits they can get from P3, and that's why they choose to form this alliance.

\section{EFFECTS OF P3 NETWORK}

Maersk, Mediterranean and CMA CGM are the world's largest three liner shipping companies. According to Maersk, P3 network would establish an independent vessel operations center in London. They would operate the ship jointly, but in the sales, market and customer service they would operate independently, keeping the competitive relationship. The average capacity of three giants of this alliance is 10300TEU, while the total capacity is $6,420,000$ TEU, accounting for $38 \%$ of the global container transport capacity. The market concentration of Asia-Europe line, transpacific line and transatlantic line would once again be promoted. P3 occupancy rate of the three mianstream lines respectively are $45 \%, 22.6 \%, 45.3 \%$, while their total share of market reaches the world's $40 \%$. P3 plans to deploy 29 routes, and 255 container ships in the three main routes, with the total capacity of the 255 container vessels are 2,600,000 TEU. In the capacity of 2600000 TEU, Maersk, Mediterranean and CMA CGM contribution rates respectively are $42 \%, 34 \%$ and $24 \%$. According to the Alphaliner, at the end of may, Maersk, Mediterranean and CMA's market shares of the world were $14.9 \%, 13.4 \%, 8.6 \%$, ranking in the world top three $(\mathrm{Xu}, 2013)$. The three totally have 102 ships with million TEU, occupying the $56 \%$ of this scale of global. In the next two years, this alliance will completely receive 28 ships of this kind, including 20 ships with 18000 TEU of Maersk.

Can be seen, when the three tycoons allied, they could optimize the allocation of resources. By sharing software, hardware, joint ventures, diversified service could improve their routes coverage, competitiveness as well as the overall reputation. By resetting and adjusting the routes, they could complement advantages, upgrade the capacity of mainstream routes, intensify liner industries. With large vessels having scale economics and exclusion effects, P3 could lead the non aligned small and medium enterprises to gaining no foothold in the mainstream routes, forcing them to withdraw from the main lines or even withdraw from the whole market. P3 not only could make them have the ability to compete with G6 Alliance and CKYH Alliance, but also could make them be able to maintain and even expand their monopoly status.

The P3 was set up as a long-term operation of sharing alliance, its formal operation need access of Europe, North America and Asia and other countries. In March this year, American Federal Maritime Commission allowed for its entry into American; in June 17th this year, after examination, Chinese MOFCOM rejected this plan for they believed that the concentration in the AsianEuropean container shipping market may eliminate, restrict competition, and operators involved in the concentration could not prove that the beneficial effects produced by P3 were significantly greater than the adverse effects and it did not conform to the society interests. Therefore, Chinese MOFCOM prohibit it. The members of P3 Network also said to respect Chinese decision, the prior relevant plans would not be implemented. P3 did not succeed, but from the reasons that Chinese prohibiting its operation could judge its significant influences.

Moreover, from the above analysis and the datas we could get that once the P3 alliance was put into operation, it would more or less have influence on 
the world shipping market structure and shipping industries. Its overall market capacity, space utilization, market planning and control and so on would be more competitive, and it would affect the whole shipping industry, port industry and the owners to a considerable degree.

\section{CONCLUSION}

Based on the Cournot Model, this article analyzed the motivations and possible effects of P3. Through the establishment of this model, the analysis shows that alliance has more scale economic benefits than that of independent entities, the alliance has complementary advantages and optimal resource allocation which lead the unit operating cost to be reduced, so as to reach higher overall profit. By way, this model is also applicable to other shipping alliances. The use of Cournot Model can be extended to more shipping alliances, it is of great significance to study the cooperation and competition of the shipping enterprises.

\section{ACKNOWLEDGEMENTS}

Scientific research fund of Jimei University, Strategies Study On Shipping Negotiating For Chinese Entering Into WTO (ZQ2012003)

\section{REFERENCES}

[1] Huo Yunkai. Study on Cooperative Effect of Strategic Alliances Based on Cournot Model. Science and Technology Management Research: 268-269.

[2] Liu Jun.2013.G6 Alliance Accelerated the integration routes.

[3] Martin.J.O.An Introduction to Game Theory. Shanghai: Shanghai University of Finance and Economics press: 5567.

[4] Xie Shiyu.2003.Economic Game Theory. Shanghai: Fudan University publishing house: 47-65.

[5] Xie Yaoyao.2010.Overview on the Research of Game Theory Competition and Cooperation Strategies of Shipping Enterprises. China Water Transport: 42-43.

[6] Xu Jianhua.2013.The Domino Effect of P3 Alliance. China Ship Survey: 42-44.

[7] Zhao Nan. The Three Big Challenges Of P3 Alliance on the Global Port Industry. China Port, 2014(3):21-22.

\section{ABOUT AUTHOR}

Ma Longjun (1988-), Female, Master Degree Candidate, Engaged in the Research of Transportation Planning and Mangement E-mail:337424092@qq.com Tel:13055512847.

Corresponding author: DengLlijuan (1973-), Female, Associate Professor, Doctor, Master Tutor, Mainly Engaged in Maritime Research E-mail: lindadeng2002@ sina.com. 